\title{
Modification and Construction of Solar Cooker Using Parabolic Reflector
}

\section{Mathew Ayoade Adedeji ${ }^{1, ~ *, ~ C h r i s t o p h e r ~ K i n g s l e y ~ U m u n n a k w e ~}{ }^{2}$, Adedayo Joseph Adesigbin ${ }^{1}$, Monsuru Olukayode Amoo ${ }^{1}$}

${ }^{1}$ Department of Agricultural and Bio-Environmental Engineering Technology, Federal Polytechnic, Ede, Nigeria

${ }^{2}$ Department of Agricultural and Bio-Environmental Engineering, Federal Polytechnic, Bauchi, Nigeria

\section{Email address:}

maadedeji@fptb.edu.ng (M. A. Adedeji)

${ }^{*}$ Corresponding author

\section{To cite this article:}

Mathew Ayoade Adedeji, Christopher Kingsley Umunnakwe, Adedayo Joseph Adesigbin, Monsuru Olukayode Amoo. Modification and Construction of Solar Cooker Using Parabolic Reflector. Engineering and Applied Sciences. Vol. 5, No. 1, 2020, pp. 28-33. doi: $10.11648 /$ j.eas.20200501.15

Received: July 13, 2019; Accepted: August 6, 2019; Published: March 2, 2020

\begin{abstract}
Energy is essential to economic and social development and improved quality of life of human being. A parabolic solar cooker was modified, fabricated and evaluated as a simple device to harness direct sun rays for cooking purposes. This device was constructed on a steel dish which was completely lined with aluminium foil. This reflecting surface was used to concentrate the rays of the sun at a focus which led to production of high temperature for cooking purposes. A cooking pot stand was erected and positioned near the focus. The equipment was tested for temperature (energy concentration) achieved at the bottom of the cooking pot, and by cooking with it. The energy concentration efficiency of the cooker was found to be $53.41 \%$. The average temperature achieved by this cooker during the time of testing was $107.38^{\circ} \mathrm{C}(380.53 \mathrm{~K})$ it was also used to cook beans and groundnuts in comparison to other alternatives such as kerosene stove and firewood. It took one hour to cook beans and 18 mins to boil groundnut. On the other hand, it took $33 \mathrm{mins}$ and $40 \mathrm{mins}$ to cook the same quantity of beans using kerosene stove and firewood, respectively while it took 10 mins and 17 mins to cook groundnuts using kerosene stove and firewood, respectively.
\end{abstract}

Keywords: Energy, Solar, Ray, Parabolic, Fabrication and Cooking

\section{Introduction}

Solar energy is being seriously considered for satisfying a significant part of energy demand in the world $[1,5,11]$. Solar energy is the energy in form of electromagnetic wave. An accurate knowledge of the solar radiation data at a particular geographical location is of vital importance for the development of solar energy devices and for estimates of their performances. All electromagnetic waves travel through space at the same speed, the velocity of light $c=2.998 \times 10^{8} \mathrm{~m} / \mathrm{s}$, and the velocity of light in air is essentially the same as its velocity in space. The power radiated by the sun into space is about $4 \times 10^{23} \mathrm{~kW}$. The fraction received by the earth is $2 \times 10^{24} \mathrm{~kW}$. These three principal natural energy sources and their contributors are stated below:

a. Geothermal energy from the earth's interior contributed about 5.2 Q per year. b. Radiated energy is derived from the sun while its energy contribution is $1.00 \mathrm{Q}$ per year.

c. Tidal energy is the energy derived from the interaction of the earth with the moon and the sun. Its contribution is $0.1 \mathrm{Q}$ per year while $\mathrm{Q}$ is the unit derived as $2.93 \times 10^{4} \mathrm{~kW}$.

Also, there are two types of solar radiation that reach the earth, one is direct-radiation this come directly without being scattered into space while the other type is diffuse radiation which comes from all direction after being turned back by the atmosphere a number of time. The sum of both type of solar radiations is termed as global radiation. The generation of energy by wind and water mills are typical examples of direct utilization [7]. Principle of operation for parabolic solar cooker; solar energy in form of short electromagnetic wave radiated on the parabolic dish, which allows rays of light on a large surface to be concentrated to a point. With the help of 
aluminium foil arrangement in the dish, the rays of light were reflected and brought to focus.

\subsection{Concentrating Collectors}

Concentration of solar radiation is achieved by using a reflecting arrangement of mirrors or a reflecting arrangement of lenses. In order to raise the intensity level received by any one square meter of the absorber, the energy received on a number of square meter, has to be reflected to, or focused on, that one square meter of absorber. This concentrates the energy that is available over a large surface by focusing it on a smaller surface. This is why this type of device is called a concentrating or focusing collector, and why the ratio of the area of intercepted sunlight to target or receiver is called the concentration ratio [8]. There are different types of concentrating collectors such as flat plate collector with plane reflectors, compound parabolic collector, and cylindrical parabolic collector. This keeps the light converging at the focal point of the parabolic section [12].

\subsection{Types of Parabolic Reflector}

Parabolic reflector is divided into two types

a. Parabolic "Dish"

b. Parabolic "Trough". But with the nature of the project parabolic 'Dish' was selected (Rahul, et al., 2017).

\section{Materials and Methods}

This study was carried out in the department of Agricultural and Bio-Environmental Engineering Technology, Federal Polytechnic, Bauchi.

\subsection{Functional Design}

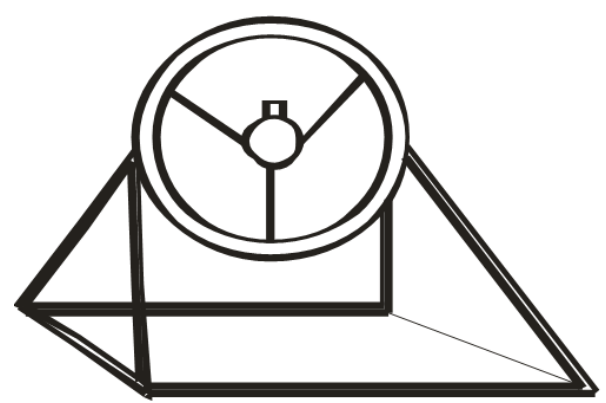

Figure 1. Schematic diagram of the solar cooker.

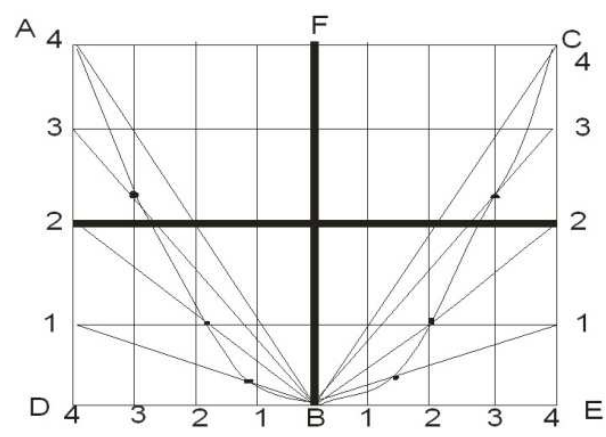

Figure 2. Conceptual parabola diagram.
Mathematically, a parabola is a conic section generated by the intersection of a right circular conical surface and a plane parallel to a generating straight line of that surface. A parabola has a single axis of reflective symmetry which passes through its focus and is perpendicular to its directed. The point of intersection of this axis and the parabola is called the vertex. A parabola spun about this axis in three dimension traces out a shape known as a paraboloid of revolution [9].

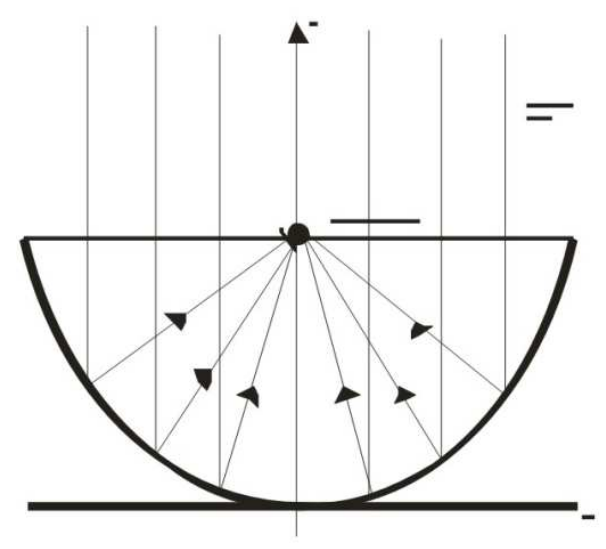

Figure 3. Paraboloid revolution diagram.

The depth of the parabola affects the height of the focus, as illustrated below:
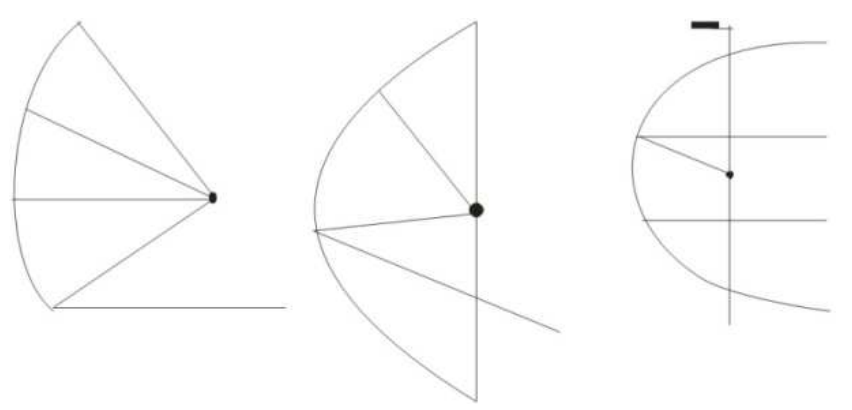

Figure 4. Effects of parabola depths on the height of the focus.

\subsection{Focus}

This is the point where the cooking is carried out on the solar cooker. This can be found by the help of simple calculations or by direct observation. The focus was found by direct observation after the dish was lined with a reflective material. A piece of cardboard was held close to the centre of the dish, and then it was moved up and down towards the sun and back.

\subsection{Potholder}

The potholder was constructed from structure made from used bike rims which allows the pot to remain level. On this rims the cookware is located and the bottom of the cooking pot was placed a little below focal point for uniform heat distribution. Regardless of the base inclination, the pot can be placed effortlessly in the cooker of solar movement, elevation of the sun, also contributes to asymmetry of the cooker. While the reflector faces the sun, the cookware remains horizontal. 
The angle between their axes may be as low as zero [11].

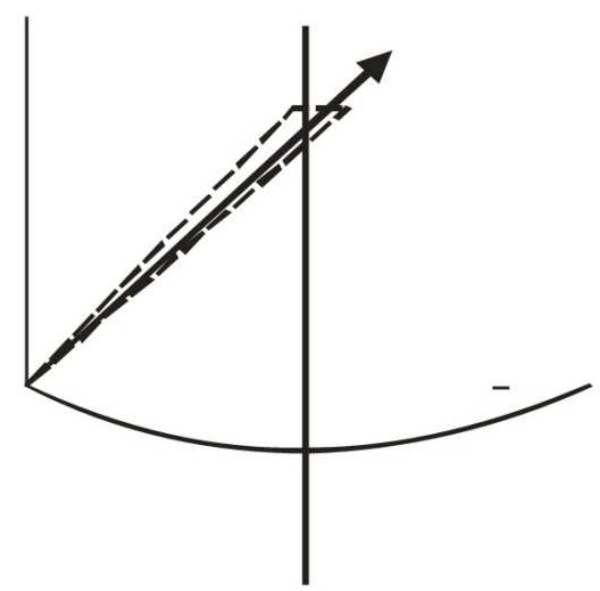

Figure 5. Diagram showing location of the potholder.

\subsection{Material Requirement of the Solar Cooker}

Materials used were locally sourced and were readily available with low cost that can be easily maintained when necessary. Materials used for this project have the following characteristics;

i. Materials are replaceable under degradation.

ii. The material can resist wind damage.

iii. The material is able to resist corrosion from saline water and distilled water.

iv. The material is portable and can be easily dismantled.

\subsection{Selection of Reflective Material}

During the time of this construction aluminum foil was used after considering many advantages of the material.

\subsection{Construction of the Solar Cooker}

a) Machine process: The solar cooker parts were produced from metal sheets, iron pipe, bicycle rim and aluminum foil. Each part was designed separately with different method and processes. The processes involved were; cutting, shaping, growing, grinding and welding.

b) Parabolic Sheet: The dish was constructed from a metal sheet of a thickness $0.5 \mathrm{~mm}$. A metal sheet of $1219.2 \mathrm{x}$ $24384 \mathrm{~mm}^{2}$ was marked out and cut using a scriber to a diameter of $1730 \mathrm{~mm}$, a square pipe of length $1730 \mathrm{~mm}$ was cut and curved to a circular form and conformed to the diameter of the metal sheet. Also a square pipe was cut and curved, and welded to the circular iron pipe in parabolic shape. These also serve as a support to the metal sheet which was cut in segmented layers and welded to the iron square pipe. The whole arrangement was now bolted to the stand made of iron square pipe $1 \frac{1}{2}$ square pipe of length $910 \mathrm{~mm}$ welded to one another 3/4 square pipe of length $665 \mathrm{~mm}$ was arranged inside the dish to hold the potholder at the focal point or parallel to the axis of the symmetry of the dish [3]. The potholder distance to the axis of the symmetry was calculated to be $624 \mathrm{~mm}$.

\subsection{Determination of the Focus}

Determination of the focus was done using cardboard paper which is a direct observation method. After the dish was lined with reflective material, a piece of cardboard was held close to the centre of the dish, and then it was moved up and down toward the sun and back. A circle of light appeared on the underside of the cardboard, when the circle is smallest, that was the position of the focus.

\subsection{General Assembly the of Solar Cooker}

The parabolic dish was covered with the reflective material (aluminum foil) using gum. The aluminum foil was arrayed properly to give sharp focal point. Though when the rays of light strikes the surface of the foil some are dispersed away, while the remaining ones converged on the pot, [10] used similar method in his study.

\section{Results and Discussions}

\subsection{Testing}

Standard testing procedures were followed and this includes testing of temperature at the focus at various intervals, measuring of the cooking time of the cooker in comparison to other alternatives such as stove and firewood and measuring of the sunshine availability at the time of cooking [4].

\subsection{Cooking}

Two varieties of food were cooked using the solar cooker, while two other energy sources were used for comparism namely, firewood and kerosene stove. These were used to cook beans and fresh groundnut and their cooking time were obtained as tabulated below, Tables 1 and 2:

Table 1. Cooking times.

\begin{tabular}{|c|c|c|c|c|}
\hline $\mathbf{S} / \mathbf{N}$ & Foods & Solar cooker & Kerosene stove & Firewood \\
\hline 1 & Beans & $1 \mathrm{~h}$ & $33 \mathrm{~min}$ & $40 \mathrm{~min}$ \\
\hline 2 & Groundnut & $18 \mathrm{~min}$ & $10 \mathrm{~min}$ & $17 \mathrm{~min}$ \\
\hline
\end{tabular}

Table 2. Analysis using method of orthogonal contrast.

\begin{tabular}{llll}
\hline Device & Cooking Time $(\mathbf{m i n})$ & ti & 78 \\
\hline Solar cooker & 60 & 18 & 43 \\
Kerosene stove & 33 & 10 & 57 \\
Firewood & 40 & 17 & 178 \\
& T... & 178 & \\
\hline
\end{tabular}




$$
\begin{aligned}
& \mathrm{n}=2, \mathrm{p}=3, \mathrm{~N}=6 S S_{U} \frac{T^{2}}{n p}=\frac{(178)^{2}}{6}=5280.67 \\
& S S_{t=} \sum \frac{T i^{2}}{n}-\frac{T^{2}}{n p}=5591-5280.67=310.33 S S_{e}=\sum x i j^{2}-\frac{T i^{2}}{n}=7002-5591=1411
\end{aligned}
$$

Table 3. ANOVA results 1.

\begin{tabular}{lllll}
\hline Sources of variation & df & SS & Ms & F \\
\hline Treatment & 2 & 310.33 & 155.17 & 0.32 \\
Error & 3 & 1411 & 470.33 & \\
\hline
\end{tabular}

$\alpha, 0.05=9.55$.

Table 4. ANOVA results 2.

\begin{tabular}{llllll}
\hline Sources of variation & df & SS & Ms & Fcal & Ftab \\
\hline Contrast 1 & 1 & 130.67 & 130.67 & 0.28 & 10.13 \\
Contrast 2 & 1 & 24.5 & 24.5 & 0.05 & 10.13 \\
Error & 3 & 1411 & 470.33 & & \\
\hline
\end{tabular}

Since Ftab $>$ Fcal at $\alpha=0.05$ both contrast will be accepted (Table 3) but contrast 2 will more accepted with the conclusion that there is no significant difference between the cooking time of the solar cooker and other alternatives (Table 4). But in another sense the solar cooker is more at an advantage compared to other alternatives because there is no cost in buying fuel and also there is no harmful effects to the environment in the solar cooker as in other alternatives.

\subsection{Temperature Readings}

The temperature of the cooker at the focus where the cooking pot is placed was measured at intervals this was done during the time of cooking. The temperatures were from 9am to $4 \mathrm{pm}$, Figure 6 :

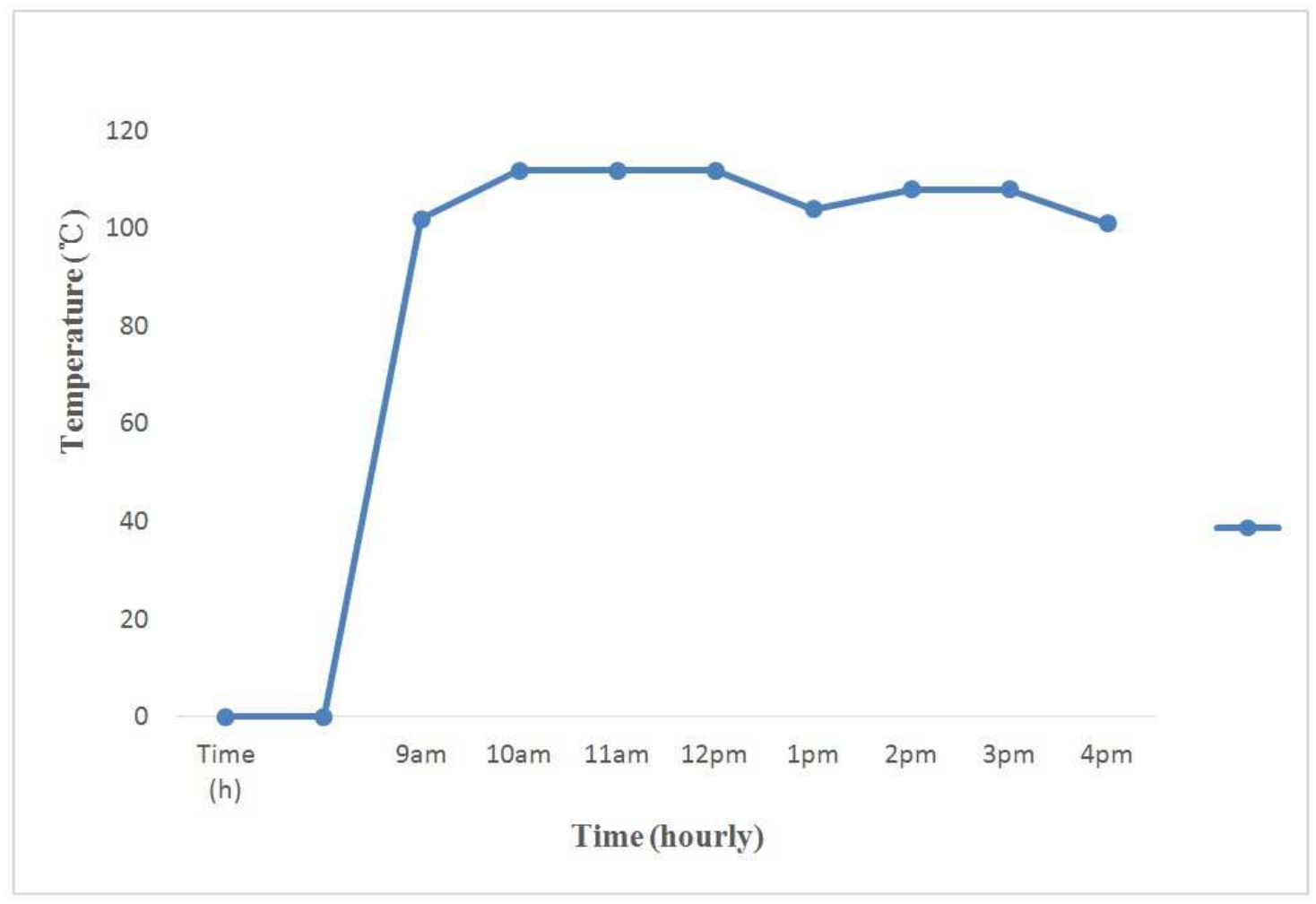

Figure 6. Temperature readings from 9 am to $4 \mathrm{pm}$.

The average temperature obtained was $107.38^{\circ} \mathrm{C}$. The temperature was measured using a glass bulb thermometer due to the non-availability of the digital thermometer.

\subsection{Sunshine Availability}

The sunshine availability for the day this testing was carried out and was measured using the sunshine record. The readings 
obtained hourly were as follows (Table 5):

Table 5. Time and readings.

\begin{tabular}{ll}
\hline Time & Reading \\
\hline $08-0900$ & 0.9 \\
$09-1000$ & 1.0 \\
$10-1100$ & 1.0 \\
$11-1200$ & 1.0 \\
$12-0100$ & 0.8 \\
$01-0200$ & 1.0 \\
$02-0300$ & 1.0 \\
$03-0400$ & 0.9 \\
\hline
\end{tabular}

Total Sunshine $7.6 \mathrm{~h}$.

Note: 0.0 - No Sunshine, 1.0 - continuous sunshine.

The sunshine recorder is an instrument use to measure the intensity of the sun. It has a sunshine card which is placed under the glass ball graduate hourly. When the sun is high and intensive enough it burns the card the level of burning is read from the card [2].

\subsection{Efficiency of the Solar Cooker}

The thermal efficiency of this cooker is calculated by the formulae equation (1):

$$
\text { Thermal Energy }=\frac{\text { Focus Enenrgy }}{\text { Energy received at the dish }}
$$

It is assumed that:

Focused energy = Energy available at the potholder

Energy received $=$ Total amount of energy radiated by the sun which strike the dish.

This was calculated using equation (2)

$$
\begin{gathered}
E=A \delta T^{4} \\
E=\text { Total amount of energy radiated } \mathrm{W} / \mathrm{m}^{2} \\
\delta=\text { Stefan constant with value } 5.7 \times 10^{-8} \mathrm{~W} / \mathrm{m}^{2} \mathrm{~K}^{4} \\
T=\text { Temperature of the surface } \mathrm{K} \\
A=\text { Area of the dish }(2 / 3) \\
A=\text { Area of the potholder }\left(\pi r^{2}\right)
\end{gathered}
$$

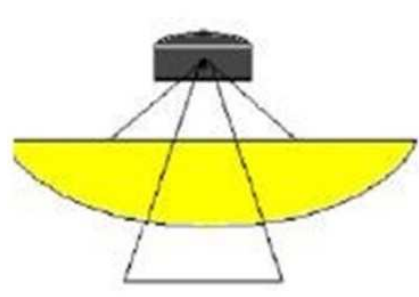

(a)

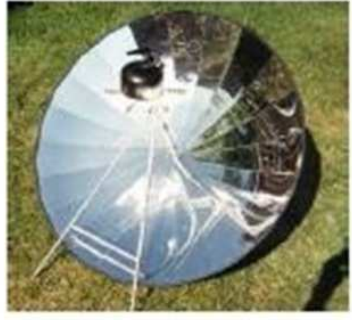

(b)

\section{References}

[1] Abdul Majeed M, Wan Mohd N. B, Khalid Bin. S and Mohd Zamri I. (2010) Reference Solar Radiation Year and Some Climatology Aspects of East Coast of West Malaysia. American J. of Engineering and Applied Sciences 3 (2): 293-299, 2010 ISSN 1941-7020.

[2] Amós. V, Azher. Z, Boaventura. C. C, Jorgen. L. and Ole. J. N. (2019). Parabolic Dish Concentrating Collector for Indirect Solar Cooking. Global Journal of Science Frontier Research: I Volume 17 Issue 1 Version 1.0 Year 2017. Publisher: Global Journals Inc. (USA). Online ISSN: 2249-4626 \& Print ISSN: 0975-5896.

[3] C. Z. M. Kimambo, (2007). Development and performance testing of solar cookers. Journal of Energy in Southern Africa, vol. 8 pp. 41-51.

[4] Elamin O. M. A and Abdalla I. A. (2015). Design, Construction and Performance Evaluation of Solar Cookers. Journal of Agricultural Science and Engineering. Vol. 1, No. 2, 2015, pp. 75-82. http://www.aiscience.org/journal/jase.

[5] J. A. Duffie and W. A. Beckman (2006). Solar Engineering of Thermal Processes. 2nd Ed., John Wiley and Sons, New York, ISBN: 978-0-471- 69867-8.

[6] Krelder and Krelth (1981). Solar Energy Handbooks Published by MCGRAN - Till Book Company New York.

incomplete reflection of this ray to the focus due to inaccurate cooking. The only thing that affects the efficiency of this cooker is when the intensity of the sun is low and there are clouds in the sky.

\section{Conclusion}

In conclusion the solar cooker with efficiency of $53.41 \%$ cooker is an efficient device which can be used to cook some foods depending on some factors such as correct production process and the sun intensity available in the area where it is

\section{Recommendations}

The following recommendations were made:
1. Anyone who wishes to improve on this project should think of a possible way to measure the energy to be used

Find a possible curvature that can trap and reflect all the

It is important that one wears a dark protective sun glasses during cooking.

\section{Conflict of Interest Statement}

There is no conflict of interest.

Figures 7. (a) and (b): Solar Parabolic Cookers (a) sketch and (b) constructed.
The efficiency of this cooker was found to be $53.41 \%$. Certainly there are losses of energy due to radiation and 
[7] Mcveiah J. C. (1982). Sun Power Introduction to the Application of solar Energy 2nd Edition, Published by pergamon press New York.

[8] Micchels. T. (1979). Solar Energy Utilization, by van Nostrand Rainhold Company New York.

[9] Muthusivagami, R. M; Velraj, R. and Sethumadhavan R. (2010). Solar cookers with and without thermal storage-a review. Renewable and sustainable energy reviews, Elsevier, 14: 691-701.
[10] Okello, D. (2012). Rock Bed Stove Suitable for Solar Cookers With Thermal Energy Heat Storage Systems. PhD Thesis. Makerere University-Uganda.

[11] Rahul. A, Manish. H and Pradeep. K. (2017). An Overview Study of Solar Cookers. International Research Journal of Engineering and Technology (IRJET). e-ISSN: 2395-0056. Volume: 04 Issue: 10 | Oct -2017. p-ISSN: 2395-0072. www.irjet.net.

[12] Sukhatme S. P. (1984). Solar Energy Principles of Thermal Collection and Storage. Published by Tata Mc. Graw-Hill Publishing Company Limited. 